\title{
Differences between Arctic Interannual and Decadal Variability across Climate States
}

\author{
JESSE REUSEN \\ Institute for Marine and Atmospheric research Utrecht, Utrecht, and Royal Netherlands Meteorological Institute, \\ De Bilt, and Astrodynamics and Space Missions, Delft University of Technology, Delft, Netherlands \\ EVELINE VAN DER LINDEN \\ Royal Netherlands Meteorological Institute, De Bilt, and Water Systems and Global Change Group, Wageningen \\ University and Research, Wageningen, Netherlands \\ RICHARD BINTANJA \\ Royal Netherlands Meteorological Institute, De Bilt, and Energy and Sustainability, Research Institute Groningen, \\ University of Groningen, Groningen, Netherlands
}

(Manuscript received 12 October 2018, in final form 18 June 2019)

\begin{abstract}
Long-term climate variations have the potential to amplify or dampen (human-induced) trends in temperature. Understanding natural climate variability is therefore of vital importance, especially since the variability itself may change with a changing climate. Here, we quantify the magnitude and other characteristics of interannual to decadal variability in Arctic temperature and their dependence on the climate state. Moreover, we identify the processes responsible for the state dependency of the variations, using five quasi-equilibrium climate simulations of a state-of-the-art global climate model with $0.25,0.5,1,2$, and 4 times present-day atmospheric $\mathrm{CO}_{2}$ forcing. The natural fluctuations in Arctic temperature, including their dependence on the state of the climate, are linked to anomalous atmospheric and oceanic heat transports toward the Arctic. Model results suggest that atmospheric heat transport leads (and also controls) Arctic temperature variations on interannual time scales, whereas oceanic transport is found to govern the fluctuations on decadal time scales. This time-scale transition of atmospheric to oceanic dominance for Arctic temperature variations is most obvious when there is interannual to decadal variability in Arctic sea ice cover. In warm climates (without Arctic sea ice cover), there is no correlation between oceanic transport and surface air temperature on any time scale. In cold climates (with full Arctic sea ice cover), interaction between ocean and atmosphere is limited, leaving poleward atmospheric heat transport to be the primary driver on all time scales (interannual and decadal).
\end{abstract}

\section{Introduction}

In the last four decades, the global climate is warming at a rate of $\sim 0.17^{\circ} \mathrm{C}$ decade $^{-1}$ (Hansen et al. 2010). This rate of warming can be obscured by naturally occurring climate fluctuations, which are superimposed on the trend. Natural fluctuations are present on all time scales, ranging from daily variations to annual, interannual, and decadal variations. In this paper, we address interannual and decadal climate variability of the Arctic region, where trends and variability are generally larger than in other regions.

Corresponding author: Jesse Reusen, jessereusen@gmail.com
Throughout history, the Earth has experienced various successive stages of warm and cold climates. For instance, during the Last Glacial Maximum (about $21 \mathrm{kyr}$ BP), global temperatures were $3^{\circ}-5^{\circ} \mathrm{C}$ lower compared to the preindustrial climate (IPCC 2014), and about $10^{\circ} \mathrm{C}$ lower in the Northern Hemispheric midlatitudes (Bintanja et al. 2005). Model simulations of the Last Glacial Maximum show that the expansion of ice sheets over North America and Eurasia caused strong changes in oceanic and atmospheric circulations (Ganopolski et al. 1998). The most recent period, known as the Holocene, experienced several millennial-, centennial-, and decadal-scale cooling events, which also involved large-scale ocean and atmosphere reorganizations (deMenocal et al. 2000; Mayewski 
et al. 2004). Clearly, atmospheric and oceanic processes are strongly dependent on the state of the climate.

The Arctic climate is very sensitive to climate forcing through the action of specific climate feedbacks, such as the ice-albedo and lapse-rate feedbacks (Curry et al. 1995; Graversen et al. 2014). Models and observations show that the Arctic warms 2-3 times as fast compared to the rest of the world (Holland and Bitz 2003; Comiso and Hall 2014), but also that the temporal variability is higher (Chylek et al. 2011). To accurately estimate the long-term (human-induced) climate trends, understanding and quantifying the variations superimposed on this trend is a necessity. When the climate changes, for instance due to an increase or decrease of the $\mathrm{CO}_{2}$ concentration in the atmosphere, these natural climate fluctuations may change as well. Decadal fluctuations can obscure or amplify long-term trends, while interannual variations can be associated with extremes. Understanding the frequency and amplitude of these variations and the associated relevant climate mechanisms, as well as the changes therein, is therefore vital.

Processes driving variability in the Arctic region each act on their own typical time scale. Consequently, processes controlling interannual variability may well differ from those associated with decadal variability. Therefore, it is important to study dominant processes active on both time scales. These governing mechanisms can effectively be subdivided in either atmospheric or oceanic processes. In this paper, the influence of anomalous heat transport through either the ocean or the atmosphere on Arctic climate variability is investigated. For decadal to multidecadal variations, it has been shown that ocean heat transport anomalies modulate sea ice cover and surface heat fluxes, with the atmosphere responding by modifying pressure patterns and circulation dynamics (e.g., Jungclaus and Koenigk 2010; Kinnard et al. 2011; Årthun and Eldevik 2016). Variability in the atmosphere is often represented by various modes, such as the North Atlantic Oscillation (NAO; Hurrell et al. 2003; Holland 2003) and the Pacific decadal oscillation (PDO; Mantua and Hare 2002; Day et al. 2012). On interannual time scales, a link was found between wintertime NAO and Arctic sea ice cover, both in models (Caian et al. 2018) and observations (Frankignoul et al. 2014). Additionally, findings by Zhang and $\mathrm{Li}$ (2017) suggest that the interannual variability in Arctic sea ice concentration is related to anomalies in the large-scale tropospheric circulation over the Northern Hemisphere, although they did not consider the importance of oceanic processes on the interannual variability in sea ice concentration. Nevertheless, these findings suggest that variations on interannual time scales are most likely associated with processes in the atmosphere, whereas anomalies in ocean heat transport have a comparatively strong impact on decadal and multidecadal time scales.

Sea ice also plays a key role in Arctic climate variability (Rind et al. 1997; Screen and Simmonds 2010), by inhibiting exchange of heat and moisture between the ocean and the atmosphere (Selivanova et al. 2016), as well as by its contribution to the ice-albedo feedback. To date, most research in Arctic climate variability has focused on Arctic decadal variability (e.g., Day et al. 2012; van der Linden et al. 2017), with less attention to interannual variations. In this paper, time scales ranging from interannual to multidecadal are considered, with a primary focus on quantifying and understanding the differences between these time scales in terms of the governing processes.

\section{Methods}

\section{a. Climate model simulations}

In this paper the dependence of Arctic interannual to decadal variability on the state of the climate is investigated. For that we need long climate records, which unfortunately are not available from observations. We therefore use a state-of-the-art global climate model (EC-Earth; Hazeleger et al. 2012). Five long (550 years) simulations have been carried out for the current climate as well as for two colder and two warmer climates. Version 2.3 of EC-Earth is used, which also contributed to phase 5 of the Coupled Model Intercomparison Project (CMIP5) (Taylor et al. 2012). EC-Earth is a fully coupled global climate model, consisting of atmospheric, oceanic, and land surface modules. The atmospheric model is the Integrated Forecast System (IFS) of the European Center for Medium-Range Weather forecasts, operating at a spectral resolution of T159 with 62 vertical levels, which contains the land module H-TESSEL (Balsamo et al. 2009). The oceanic model is the Nucleus for European Modeling of the Ocean (NEMO) model (Madec 2008), developed by the L'Institut Pierre-Simon Laplace (IPSL). It has a horizontal resolution of about $1^{\circ}$ and contains 42 vertical levels. Incorporated in NEMO is the Louvain-la-Neuve sea ice model version 2 (LIM2) (Fichefet and Maqueda 1997; Goosse and Fichefet 1999), which is a dynamicthermodynamic sea ice model. Coupling of the atmospheric and oceanic components is performed using the Ocean, Atmosphere, Sea Ice, Soil (OASIS) coupling module (Valcke et al. 2003).

All simulations use a spinup of roughly a thousand years of preindustrial forcing, followed by 44 years of spinup with present-day forcing. Hereafter, the $\mathrm{CO}_{2}$ 

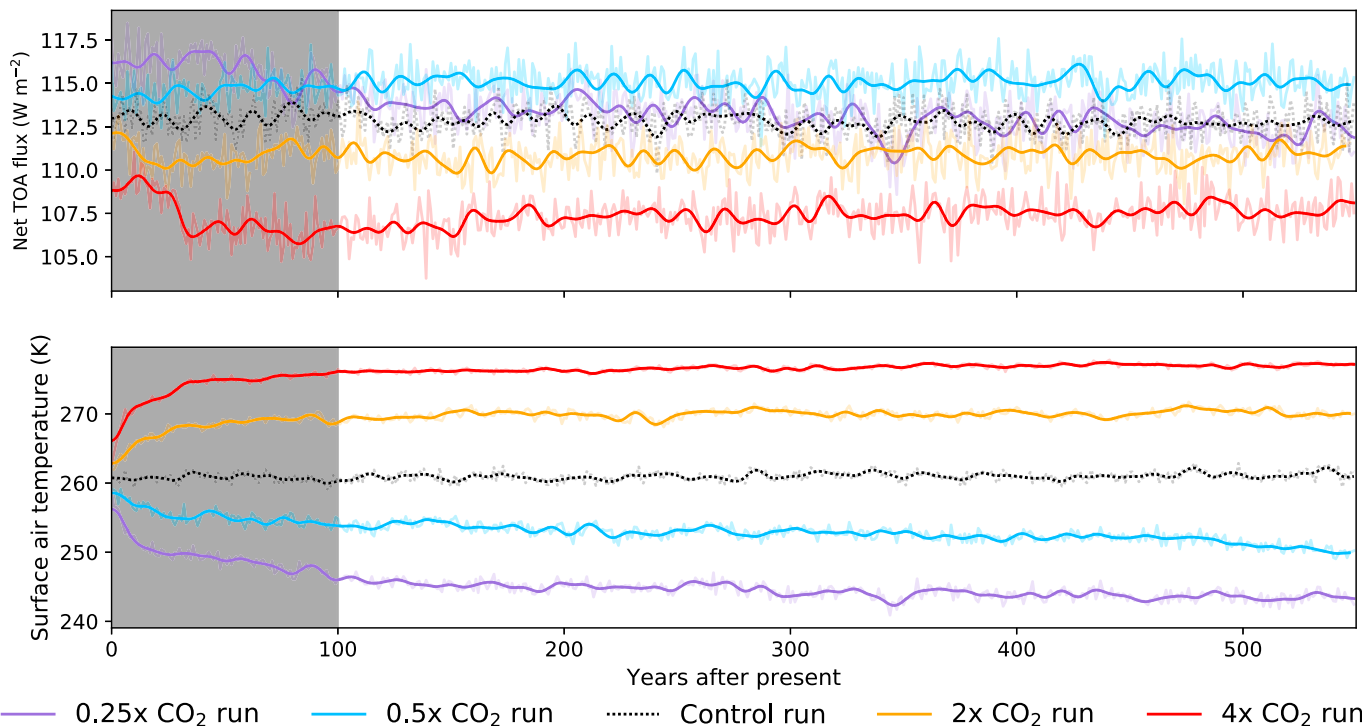

FIG. 1. Full time series of the Arctic surface air temperature and net flux at the top of atmosphere for each simulation. The thick lines are the decadal variations, while the more transparent lines represent the full time series. The nonshaded area is used in the rest of the analyses, and the climates are assumed to be in quasi-equilibrium after 100 years.

concentration is instantaneously set to a fixed value. In the five simulations used here, the carbon dioxide $\left(\mathrm{CO}_{2}\right)$ concentration in the atmosphere is set to $0.25 \times, 0.5 \times$, $1 \times, 2 \times$, and $4 \times$ the value of the year 2000 (present day, $368.9 \mathrm{ppm}$ ). Each simulation is then run for 550 years. During the last 450 years of each simulation, the climate is assumed to be in a quasi-equilibrium state (Fig. 1); the first 100 years are considered spinup to the respective climate states and are not used in the analysis. All data used here are annually averaged, aside from section $3 \mathrm{e}$ on leads and lags, where a 12-month running mean has been applied in order to calculate the lag in months.

To remove any remaining trend in the five 450-yr time series, all data are linearly detrended prior to the analyses. Changes in Arctic climate variability can then be studied in warmer or colder climates by comparing results to the control run. In this way, the changes in amplitude and frequency of the Arctic climate fluctuations and the processes responsible for these changes can be quantified and linked to the relevant climate mechanisms.

High- and low-frequency variations (i.e., interannual versus decadal) are analyzed separately. This is achieved by applying a fourth-order Butterworth filter. Low frequencies are filtered using a fourth-order high-pass filter with a cutoff frequency of $0.1 \mathrm{yr}^{-1}$, high frequencies are filtered using an equivalent low-pass filter. Its effect is illustrated in Fig. 2, which shows total Arctic sea ice area anomalies of the detrended time series of the $0.25 \times \mathrm{CO}_{2}$ simulation and the high-pass and low-pass filter. We decided to choose 10 years as a boundary, to separate interannual and decadal variability, and to remain consistent with van der Linden et al. (2017). Frequency spectra show clear peaks at time scales larger than 10 years, as well as several maxima associated with time scales smaller than that. The time scales associated with these maxima are different across all climates. Clearly, oceanic and atmospheric processes work on different time scales, but these are sometimes hard to disentangle. For consistency we have chosen to stick with the same definition across all climates. The same analysis has been done with cutoff frequencies of 8 and 12 years, but this did not affect the outcomes and main conclusions of this study.

\section{b. Arctic heat budget}

This section sketches the theoretical background of the energy budget. The energy budget of the Arctic $\left(70-90^{\circ} \mathrm{N}\right)$ as given in Nakamura and Oort (1988) and Serreze et al. (2007) is

$$
\frac{\partial E_{\mathrm{atm}}}{\partial t}=F_{\mathrm{SFC}}-F_{\mathrm{TOA}}-\nabla \cdot \mathrm{AHT} .
$$

For the atmosphere, the net heat gain or loss $\left(\partial E_{\mathrm{atm}} / \partial t\right)$ is the sum of the net flux at the surface $\left(F_{\mathrm{SFC}}\right)$, the net flux at the top of the atmosphere $\left(F_{\mathrm{TOA}}\right)$ and the convergence of the atmospheric heat transport at the sides $(-\nabla \cdot$ AHT $)$. The fluxes at the top of the atmosphere and at the surface are defined as positive upward, and the atmospheric heat transport is defined positive when 


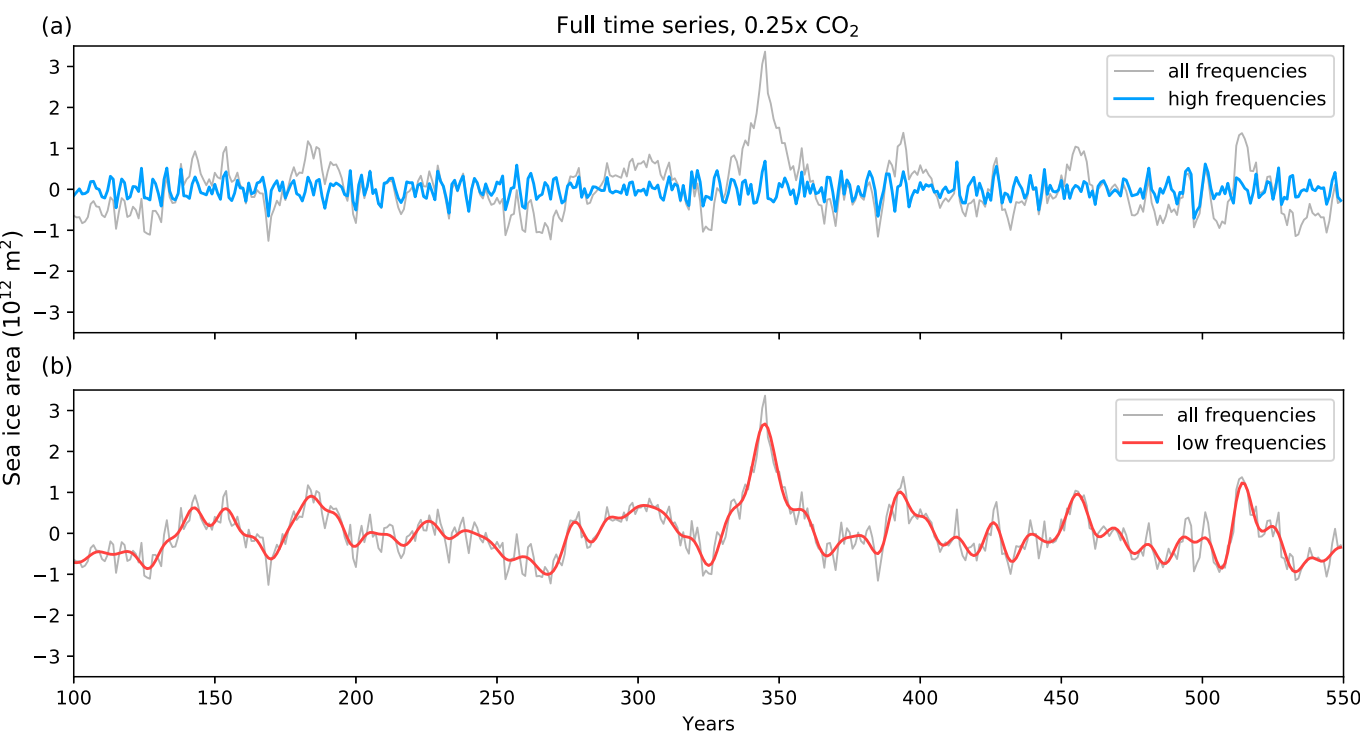

FIG. 2. Effect of the (a) high-pass and (b) low-pass Butterworth frequency filter with a cutoff frequency of $0.1 \mathrm{yr}^{-1}$ on the full time series of the total annual sea ice area in the $0.25 \times \mathrm{CO}_{2}$ run.

directed northward (Fig. 3). The net energy gain or loss is equal to zero, since the climate system is assumed to be in semisteady state. The atmospheric heat transport can subsequently be calculated as the difference between $F_{\mathrm{TOA}}$ and $F_{\mathrm{SFC}}$. The total sea ice area in the Northern Hemisphere is calculated by multiplying the sea ice concentration with the corresponding area.

Similarly, the energy budget of the ocean can be expressed as

$$
\frac{\partial E_{\mathrm{oc}}}{\partial t}=-F_{\mathrm{SFC}}-\nabla \cdot \mathrm{OHT}
$$

The net heat gain or loss of the ocean is the sum of the net flux at the surface and the convergence of the ocean heat transport through the sides $(-\nabla \cdot$ OHT $)$. For the ocean, because of its larger inertia, the steady-state assumption does not hold and $\partial E_{\mathrm{oc}} / \partial t$ needs to be calculated explicitly. This term is calculated as the change in ocean heat content in the Arctic over time, where we follow Dijkstra (2008) for the calculation of the ocean heat content:

$$
E_{\mathrm{oc}}=\rho_{0} c_{p} \int_{0}^{\max (\mathrm{depth})} T d z
$$

where the depths are defined positive downward, $\rho_{0}=$ $1035 \mathrm{~kg} \mathrm{~m}^{-3}$ is the reference density of seawater (also used in NEMO), $c_{p}=3992 \mathrm{~J} \mathrm{~kg}^{-1} \mathrm{~K}^{-1}$ is the heat capacity of seawater, and $T$ is the temperature at a certain depth.

\section{Results}

\section{a. Characteristics of the Arctic}

\section{1) Mean state}

Due to the lack of long observational records of the Arctic climate, we use EC-Earth to evaluate climate variability. The inherent assumption is that EC-Earth accurately represents the real climate system. In this section we use observationally driven reanalyses data to infer how good this assumption is for the Arctic climate and its variability.

The atmospheric $\mathrm{CO}_{2}$ concentration exhibits a nonlinear relationship with both temperature and total sea ice area, because radiative forcing depends roughly on

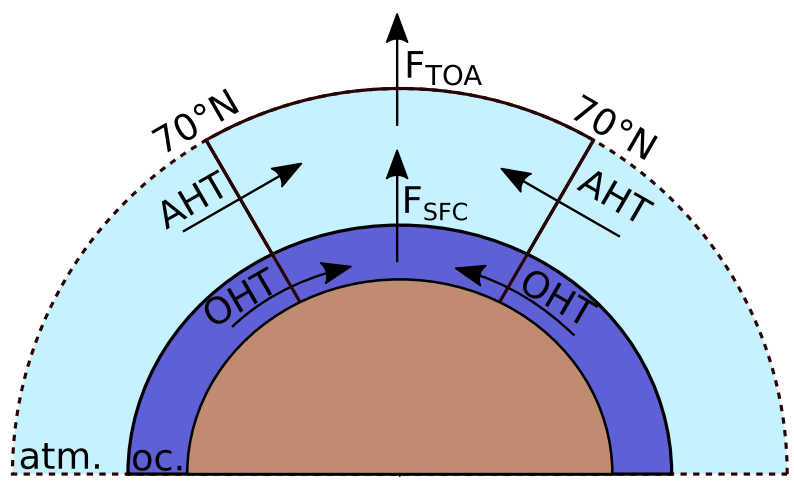

FIG. 3. Schematic view of the energy budget in the Arctic. AHT and OHT are the heat transport trough the atmosphere and the ocean, respectively; $F_{\mathrm{TOA}}$ and $F_{\mathrm{SFC}}$ represent the net fluxes at the top of the atmosphere and at the surface. 
TABLE 1. Simulation name, mean Arctic temperature $(\mathrm{K})$ in summer $\left(T_{\mathrm{JJA}}\right)$ and winter $\left(T_{\mathrm{DJF}}\right)$, and the total Northern Hemispheric sea ice area $\left(10^{6} \mathrm{~km}^{2}\right)$ in September $\left(\mathrm{SIA}_{\min }\right)$ and March $\left(\mathrm{SIA}_{\max }\right)$. Estimates of observationally driven reanalyses products have been added for comparison. To validate surface air temperature, data from ERA-Interim (Dee et al. 2011), NCEP/CSFR (Saha et al. 2010), and NASA MERRA-2 (Gelaro et al. 2017) have been used. These are all reanalysis datasets, with values for $T_{\mathrm{JJA}}$ of 274.7, 274.0, and 274.0 K, respectively. Values for $T_{\mathrm{DJF}}$ are 249.1, 249.4, and 250.9 K. For the sea ice area, bootstrap sea ice concentrations from Nimbus-7 SMMR and DMSP SSM/I-SSMIS, version 3, from NSIDC are used (Comiso 2017). All reanalysis datasets have been averaged over the period 1990-2010.

\begin{tabular}{lcccccr}
\hline \hline Simulation & $0.25 \times \mathrm{CO}_{2}$ & $0.5 \times \mathrm{CO}_{2}$ & Control & $2 \times \mathrm{CO}_{2}$ & $4 \times \mathrm{CO}_{2}$ & Reanalysis/obs based \\
\hline$T_{\mathrm{DJF}}$ & 226.9 & 237.5 & 248.8 & 263.6 & 272.0 & 249.8 \\
$T_{\mathrm{JJA}}$ & 266.7 & 270.7 & 273.8 & 277.2 & 282.4 & 274.2 \\
SIA $_{\max }$ & 27.8 & 21.1 & 15.8 & 10.9 & 0.61 & 11.5 \\
SIA $_{\min }$ & 17.7 & 12.0 & 5.37 & 0.14 & 0.12 & 4.76 \\
\hline
\end{tabular}

the logarithm of atmospheric $\mathrm{CO}_{2}$ content. This is clearly illustrated in Table 1, which shows Arctic mean temperature for summer and winter, as well as the average maximum and minimum sea ice area. Reanalyses data have been added for comparison. Overall, the surface air temperature in the control run of EC-Earth is $0.4^{\circ}$ lower in winter and about $1^{\circ}$ lower in summer as compared to results obtained from the observation-based data. The seasonal maximum and minimum sea ice area are larger in EC-Earth, as anticipated considering the lower average temperatures. In fact, the average sea ice area is heavily overestimated by EC-Earth compared to other global climate models. Biases are larger in winter $\left(4.5\right.$ million $\left.\mathrm{km}^{2}\right)$ than in summer (about 1 million $\mathrm{km}^{2}$ ), but both show the clear need for a better representation of sea ice in EC-Earth.

Winter warming (cooling) is amplified as compared to summer warming (cooling) (Bintanja and van der Linden 2013). As a result, the seasonal cycle of the temperature is enhanced in colder climates, with a seasonal temperature difference of about $40^{\circ}$ in the coldest simulation as compared to only $10^{\circ}$ in the warmest simulation. The amplitude of the seasonal cycle in sea ice area in general does not vary a lot between the climates, with the exception of the $4 \times \mathrm{CO}_{2}$ climate, where practically no sea ice is left in any of the seasons. The seasonal cycle of the sea ice area is, however, potentially dependent on more factors, such as wind patterns (Comiso 2006), downward longwave radiation fluxes (Francis and Hunter 2006) and the geometry of the region (Eisenman 2010).

Energy budgets are analyzed for the warmest, coldest, and control climate to infer the order of magnitude and direction of the mean energy fluxes in the Arctic (Fig. 4). The directions of the mean fluxes are the same across all climates. The Arctic region is characterized by a convergence of both the atmospheric and oceanic heat flux, set up by the meridional temperature gradient due to differential heating by the sun. For annual mean fluxes, the convergence of the heat fluxes is primarily compensated by longwave radiation to space (Serreze and Barry 2011). The annual mean net surface flux is directed upward. It decreases for colder climates, due to increased sea ice cover inhibiting the exchange of heat between the ocean and the atmosphere. The net flux at the top of the atmosphere (TOA) is composed of net incoming shortwave radiation and net outgoing longwave radiation and does not seem to change between climates. In a warmer climate, the sea ice area is smaller, resulting in a lower albedo. Consequently, a larger fraction of the shortwave radiation is being absorbed at the surface, thus reducing TOA upward shortwave flux. The associated surface and lower atmospheric warming, however, increase the upward longwave radiation at TOA. These two processes largely compensate each other.

In the ocean, there is in general a gain of heat for warm climates, very little heat gain or loss for the control climate, and heat loss for cold climates, supporting the notion that the ocean is not in equilibrium after the first 100 years of the simulation. The magnitude of the oceanic transport is clearly smaller than that of the atmospheric heat transport (for the control run, values are $\sim 10 \mathrm{~W} \mathrm{~m}^{-2}$ for OHT and $\sim 100 \mathrm{~W} \mathrm{~m}^{-2}$ for AHT), as was previously observed by Trenberth and Caron (2001). Whereas the mean AHT decreases for warmer climates, the mean OHT increases. A combination of wind driven changes in ocean currents and changes in temperature differences between the Atlantic and the Arctic Ocean causes this net increase of the OHT in the warmer climates. There is no net increase or decrease of the volume transport (van der Linden et al. 2019).

Furthermore, sea ice limits the exchange of heat and momentum, which influences both heat and volume transport. The larger AHT is likely related to the increased meridional temperature gradient (Manabe and Wetherald 1980) in colder climates. The total heat transport (OHT + AHT) through $70^{\circ} \mathrm{N}$ stays the same across the climates. The decrease in atmospheric heat transport is compensated by the increase in oceanic heat transport (and vice versa), a compensation process 

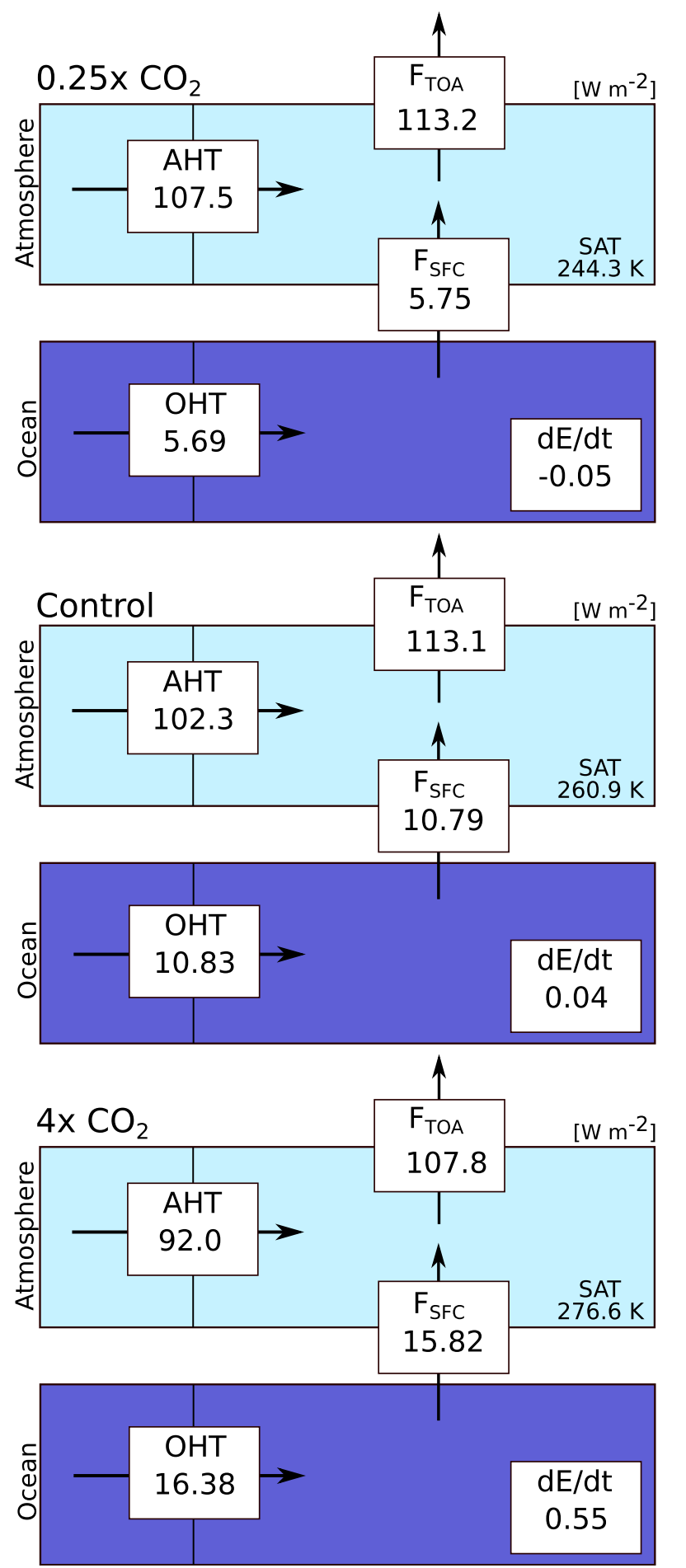

FIG. 4. Schematic of the annual mean fluxes in and out of the Arctic, as well as the energy heat gain or loss of the ocean (all values in $\mathrm{W} \mathrm{m}^{-2}$ ). The equilibrium temperature is indicated in the bottom right of the atmospheric box. known as Bjerknes compensation (Bjerknes 1964). This compensation mechanism is consistently present in recent fully coupled climate models (Outten et al. 2018) and explained in more detail in section $3 \mathrm{~b}$.

\section{2) Arctic VARIABILITy}

The standard deviations of annual mean surface air temperature (SAT), sea ice area (SIA), and mean fluxes are shown in Fig. 5 for all climate states. To get an estimate of the accuracy of these values, error bars are calculated by dividing the 450 years of data into 9 bins of 50 years. The standard deviation of each of the bins is determined and a $t$ test with a $95 \%$ significance interval is used to determine the error. By binning the data into blocks of 50 years, the decadal variability on long time scales is not captured very well, since, for example, only one cycle is present for a variability with a time scale of 50 years. In this method, the variability on time scales longer than 50 years is not accounted for, while these fluctuations are present in the full time series. Standard deviations in SAT and SIA from observation-based data have been added for comparison. From these datasets, the largest common period (1981-2010) is used. Due to the lack of long observational records with good temporal and spatial resolution, only the interannual variability can be assessed in these reanalyses datasets. Interannual variability in SAT in the control run of EC-Earth compares well to the reanalysis, with a standard deviation just below $0.5 \mathrm{~K}$. In general, variability in SAT decreases toward warmer climates, in accordance with data from temperature proxies ranging from the Last Glacial Maximum (about 21 kyr BP) to the Holocene (last 11 kyr; Rehfeld et al. 2018).

For the total Northern Hemispheric SIA, decadal variability is larger than interannual variability by factors running from just below 1.4 in the control experiment to just below 2.5 in the $0.25 \times \mathrm{CO}_{2}$ experiment. Taking the control run as a reference we see that, with the exception of the $4 \times \mathrm{CO}_{2}$ run, interannual variability in sea ice area does not change between the five climates, while decadal sea ice variability increases toward both warmer and colder climates. In a colder climate, the sea ice is not bound by continents and can grow or shrink more freely in response to forcing (Goosse et al. 2009; Eisenman 2010). The same principle applies to the $2 \times \mathrm{CO}_{2}$ climate, in which the sea ice edge is not near the continental boundaries of the Arctic Ocean. In the current climate, however, the continental boundaries are limiting sea ice growth and variability in sea ice area. This explains why decadal variability is reduced for the control simulation, as compared to the $2 \times \mathrm{CO}_{2}$ and $0.5 \times \mathrm{CO}_{2}$ simulations. Percentage changes in decadal variability (with regards to the mean sea ice area) are 

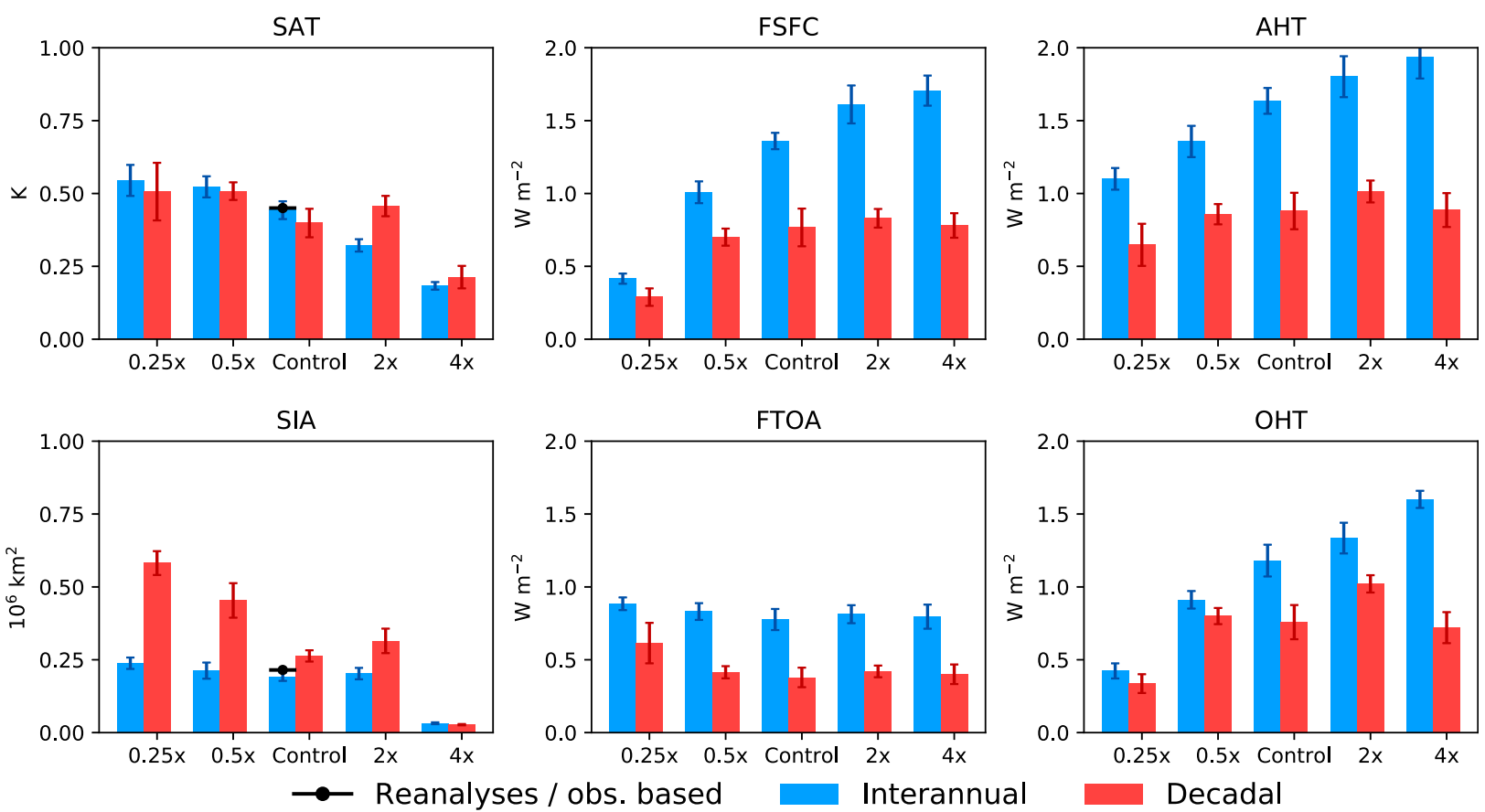

FIG. 5. Standard deviation of the surface air temperature $(\mathrm{K})$ in the Arctic $\left(70^{\circ}-90^{\circ} \mathrm{N}\right)$, the sea ice area $\left(10^{6} \mathrm{~km}^{2}\right)$, the net flux at the surface $\left(F_{\mathrm{SFC}}\right)$ and at the top of the atmosphere $\left(F_{\mathrm{TOA}}\right)$ (both in $\left.\mathrm{W} \mathrm{m}^{-2}\right)$. Finally, the standard deviation of the heat transport through the atmosphere (AHT) and through the ocean (OHT) are also shown (in $\mathrm{W} \mathrm{m}^{-2}$ ). Values are annual means, averaged over the Arctic and for interannual and decadal variability. To get an idea of the uncertainty in the standard deviations shown here, the error bars are determined by performing a $t$ test with a $95 \%$ significance interval to the standard deviations of nine bins of 50 years of data. Reanalyses and an observation-based dataset have been added (same as described in Table 1) to validate surface air temperature and sea ice area variability in EC-Earth. The values found for the standard deviation of the surface air temperature interannual variations in the reanalyses datasets are $0.47,0.41$, and $0.46 \mathrm{~K}$ for ERA-Interim, NASA MERRA-2, and NCEP/CSFR, respectively.

similar for simulations with year-round sea ice $(0.25 \times$ $\mathrm{CO}_{2}, 0.5 \times \mathrm{CO}_{2}$, and control). The standard deviation in the $4 \times \mathrm{CO}_{2}$ is small, since there is little to no sea ice. Despite the discrepancy in the average SIA observed earlier, interannual variability is captured well in the control run of EC-Earth as compared to the observationbased datasets.

For surface fluxes (averaged over $70^{\circ}-90^{\circ} \mathrm{N}$ ), interannual variability is about $1.4-2$ times as large as decadal variability. The variability in surface fluxes increases toward warmer climates, especially for interannual fluctuations. In experiments where the Arctic Ocean is partially covered by sea ice, surface heat flux is dominated by that of the (seasonally) ice-free regions. In a warmer climate, this ice-free region is larger. Together with an increased variability in the sea ice cover, this allows for larger surface fluxes and variations herein. The standard deviation of AHT and OHT increases toward warmer climates, mostly for interannual variations. In a warming climate, the dry static flux decreases, because of the decreased temperature gradient between the equator and the poles. The latent heat transport increases, as a result of the increased water vapor content (Graversen and Burtu 2016; Hwang et al. 2011). At $70^{\circ} \mathrm{N}$, most northward energy transport is latent heat transport. In first order, the variability scales with the mean. Therefore, the variability is dominated by the latent heat transport. The latent heat transport increases toward warmer climates, and with it also its variability. At the same time, variability could be enhanced or decreased by changes of large-scale circulation patterns. Variability in net TOA flux does not show a clear dependence on the state of the climate.

\section{b. Spatial patterns in temperature variability related to poleward heat transport}

In the previous sections, we learned that the mean and standard deviation of the Arctic temperature is dependent on the state of the climate. The next step is to look at the processes driving this variability. One of the mechanisms responsible is the meridional heat transport, either through the atmosphere or the oceans. Here, we assess the impact of anomalies in atmospheric and oceanic heat transport on Arctic temperature variability and its dependence on the time scale by looking at regression maps and assessing interannual and decadal 


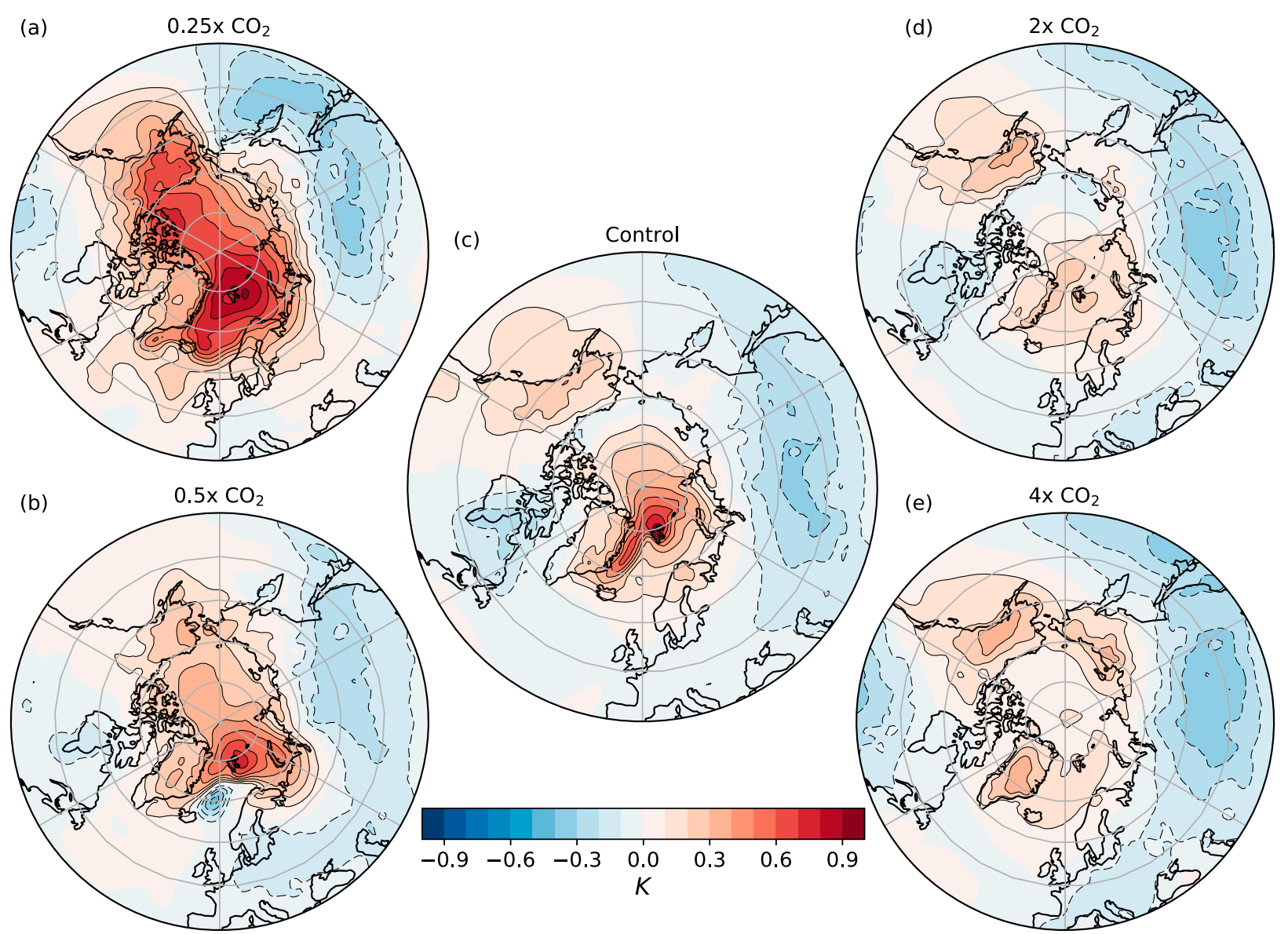

FIG. 6. Regression maps of the surface air temperature on the atmospheric heat transport through $70^{\circ} \mathrm{N}$ for interannual variations. Values have been scaled by the standard deviation of AHT.

variability separately. In general, patterns of AHT and OHT are similar, but of opposite sign. For this reason, only plots of the regression on AHT are shown.

Due to its smaller inertia, the atmosphere is expected to control Arctic temperature variations on interannual time scales. Therefore, for interannual variability, positive values are expected when regressing Arctic temperature on AHT through $70^{\circ} \mathrm{N}$. This is confirmed in Fig. 6. Across all climates, positive values are found over the Arctic Ocean, accompanied by small negative values over the Siberian region, thereby bearing resemblance to the imprint of the AO index on the temperature. However, no significant relation has been found between the $\mathrm{AO}$ and $\mathrm{T} 2 \mathrm{M}$ on interannual time scales $(|r|<0.12)$ for the two coldest climates, while for the $1 \times \mathrm{CO}_{2}$ simulation, correlation between $\mathrm{AO}$ and T2M is barely significant $(r=-0.15)$. Nonetheless, AO and $\mathrm{T} 2 \mathrm{M}$ do exhibit a significant relation for both the $2 \times \mathrm{CO}_{2}(r=-0.25)$ and $4 \times \mathrm{CO}_{2}(r=-0.45)$ climate. Correlations are negative as the positive temperature anomalies caused by the $\mathrm{AO}$ reach less far into the
Arctic on the European side, while negative anomalies occupy a larger region on the Canadian side (van der Linden et al. 2017). In Fig. 6, most pronounced positive regressions are found in the $0.25 \times \mathrm{CO}_{2}$ run. Overall, averaged over the Arctic, a positive anomaly in AHT leads to a positive anomaly in SAT for interannual variations.

On decadal time scales, poleward ocean heat transport governs Arctic temperature variability (e.g., Goosse and Holland 2005; Zhang 2015; van der Linden et al. 2016). A regression of SAT on OHT results primarily in positive values, concentrated around the sea ice edge (not shown). In these regions, fluctuations in surface fluxes passing on anomalies in OHT are largest and consequently impact SAT variability the most. Regressing AHT through $70^{\circ} \mathrm{N}$ with temperatures in the Arctic region, on the other hand, show hardly any positive values (Fig. 7). In fact, many regions exhibit negative values that arise due to Bjerknes compensation (Bjerknes 1964). A positive Arctic temperature anomaly associated with OHT entails a reduction in heat 


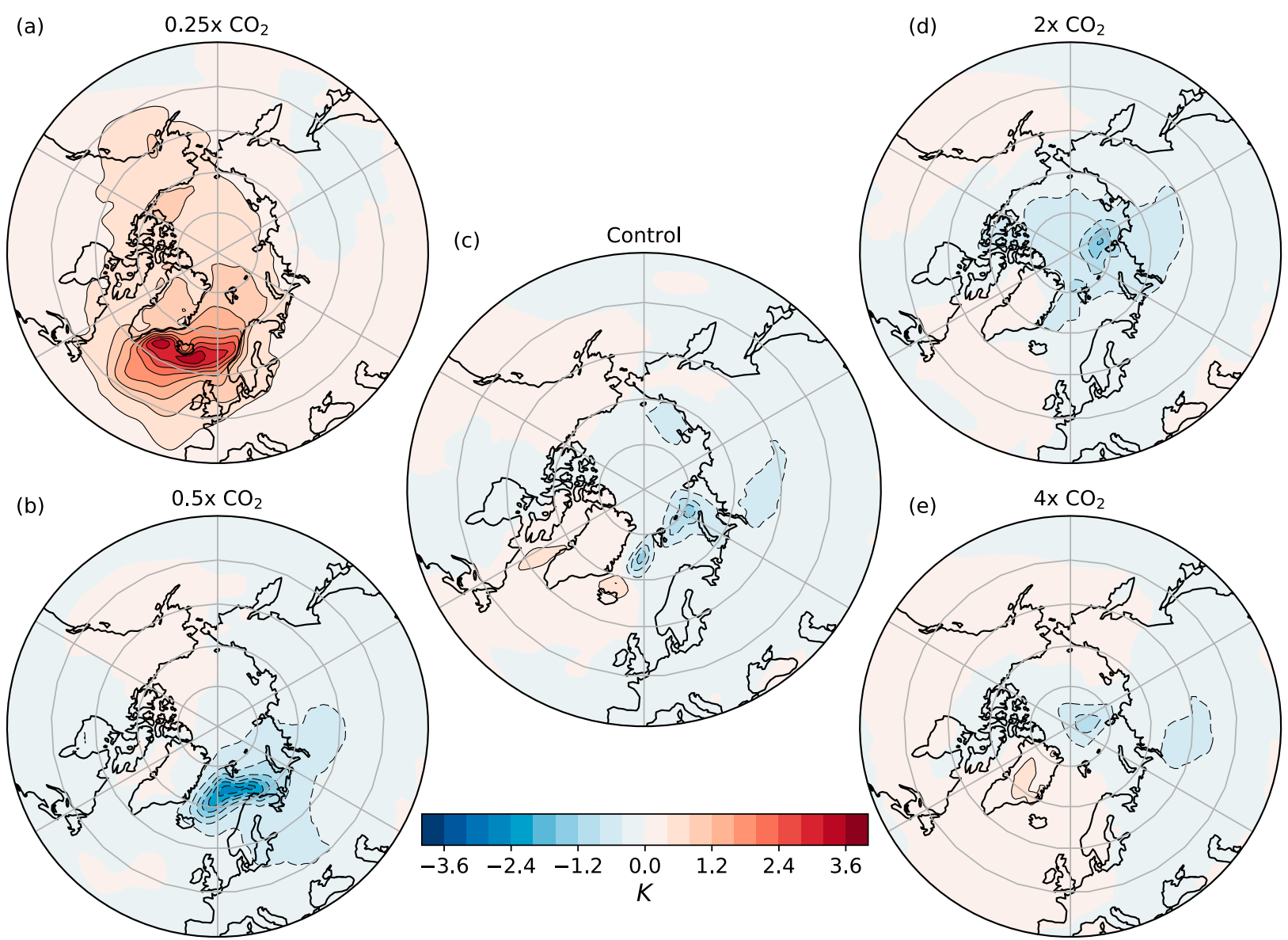

FIG. 7. Regression maps of the surface air temperature on the atmospheric heat transport through $70^{\circ} \mathrm{N}$ for decadal variations. Values have been scaled by the standard deviation of AHT. Note that the scale is 4 times as large as for interannual variations.

difference between the equator and the poles, resulting in a reduced poleward heat transport through the atmosphere, explaining the negative regression for positive temperature anomalies. Zhao et al. (2016) find that Bjerknes compensation is most prominent for lowfrequency variability (time scales $>10$ years). For the $0.25 \times \mathrm{CO}_{2}$ simulation, however, large positive values for the regression of SAT on AHT are found (Fig. 7a). Here, the region from $70^{\circ}$ to $90^{\circ} \mathrm{N}$ is completely covered by sea ice. Therefore, there is little interaction between the atmosphere and the ocean and AHT remains positively correlated with SAT. In an attempt to find the underlying mechanisms responsible for these positive values, the sensitivity to our choice in area is tested. When the regression is made on AHT through $60^{\circ} \mathrm{N}$, the area (now $60^{\circ}-90^{\circ} \mathrm{N}$ ) is in none of the climates fully covered by sea ice and negative values are found across all five climates (not shown). A regression of the temperature on the atmospheric heat transport through $80^{\circ} \mathrm{N}$ (also not shown), on the other hand, results in positive values for both the $0.25 \times \mathrm{CO}_{2}$ and the $0.5 \times \mathrm{CO}_{2}$ simulation, since the area from $80^{\circ}$ to $90^{\circ} \mathrm{N}$ is now completely covered by sea ice in the two cold climates. This shows that the choice of the region in relation to the coverage by sea ice should be taken into account while interpreting these results.

\section{c. Time-scale dependency}

All processes induce variations on their own typical time scale. This is illustrated in Fig. 8, which shows correlations between SAT, AHT, and OHT as a function of the periodicity. Specific frequency bins are used, filtered by a fifth-order Butterworth bandpass filter. To get a good resolution for interannual variations, the width of the bins increases logarithmically, ranging from $10^{-2.15}-10^{-1.65} \mathrm{yr}^{-1}$ to $10^{-0.55}-10^{-0.05} \mathrm{yr}^{-1}$ (corresponding to bins with a period of 45-140 years and 1.1-3.5 years), thereby keeping a constant difference of 0.5 in the exponential. A running correlation is then performed. The frequency assigned to a certain band is that of the average of the minimum and maximum frequency of that band. Insignificant correlations are 


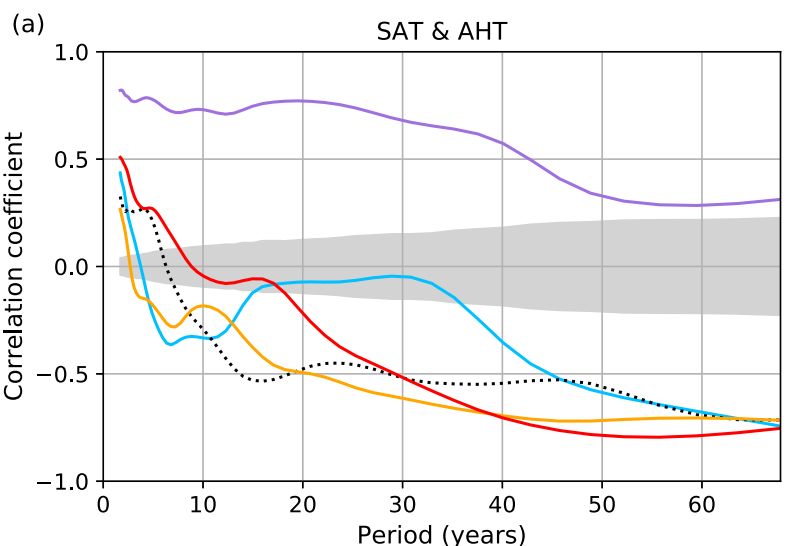

(b)
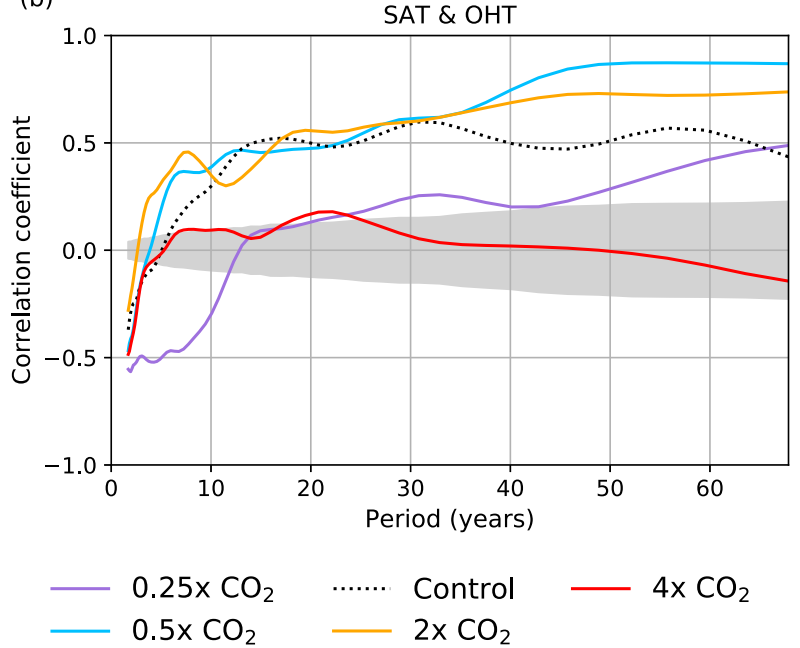

FIG. 8. Correlation for variations on specific frequency bins as a function of periodicity. The period on the $x$ axis denotes the central period of the window used. Correlations are calculated with a zero time lead/lag. The shaded area indicates the region where correlations are insignificant as determined by performing a block bootstrap on the data (using 1000 samples) before applying a frequency filter.

determined by performing a block bootstrap on the data (using 1000 samples) before applying a frequency filter. In this method, the data are divided in blocks of 10 and then randomly shuffled. Each block consists of 10 data points, to correct for any possible autocorrelations. The shuffled data are then split into frequency bins. For each frequency bin, correlations are calculated with another randomly shuffled variable. The correlation values of the randomly shuffled data at the $99 \%$ interval are then set as the boundaries for significance and are shown by the shaded area in Fig. 8.

Intuitively, on interannual time scales ( $<10$ years), correlations between SAT and AHT would be positive, whereas on decadal time scales ( $>10$ years), correlations between SAT and OHT are expected to be positive, as explained earlier. For positive correlations, a positive anomaly in SAT is associated with a larger poleward AHT. For the $0.5 \times \mathrm{CO}_{2}$, the control and the $2 \times \mathrm{CO}_{2}$ run, this holds. For the other two runs, the Arctic stands out by either being fully covered by sea ice $\left(0.25 \times \mathrm{CO}_{2}\right)$ or by being completely devoid of sea ice. In a fully covered Arctic, the presence of sea ice inhibits exchange of heat and moisture between the ocean and the atmosphere. This puts a limit on the amount of heat that can be passed on from the Arctic Ocean to the atmosphere and vice versa. Variability in SAT consequently remains associated to variations in atmospheric transport on all time scales (Fig. 8a). In an Arctic completely absent of sea ice, ocean heat transport is not significantly correlated to SAT on all time scales (Fig. 8b). Large-scale atmospheric and oceanic circulation changes could be at play here (Mayewski et al. 2004). Density profiles might provide more insight in what is happening. In warmer climates, the surface stratification greatly increases, making it difficult to mix heat downward (Fig. A1), thereby impacting surface fluxes and hence surface air temperatures. Sea surface temperatures are no longer restricted to the melting point temperature in these climates and much higher values can be reached (Fig. A2). An increase in temperature difference promotes diffusion and as this is a slow process, the deep oceans in the $4 \times$ $\mathrm{CO}_{2}$ and $2 \times \mathrm{CO}_{2}$ simulations are not yet in equilibrium (as apparent from Figs. A1 and A2). However, the $4 \times$ $\mathrm{CO}_{2}$ run in Fig. 8a does not differ from that in the climates containing $0.5 \times, 1 \times$ and $2 \times \mathrm{CO}_{2}$, so it appears the relation between atmospheric transport and temperature variability has not changed drastically as compared to the other climates. It remains difficult to draw conclusions about the mechanisms at play in this warm climate from the density, salinity and temperature profiles alone. Further research needs to be done to test the robustness of this hypothesis.

The previously described Bjerknes compensation (Bjerknes 1964) explains the negative correlations between SAT and AHT on decadal and multidecadal time scales. For Bjerknes compensation, marginal ice zones are critical (Van der Swaluw et al. 2007; Outten and Esau 2017). Increased OHT leads to a decrease of sea ice in these zones. This results in increased fluxes and higher local temperatures, thereby changing the pressure patterns and the atmospheric flow (Jungclaus and Koenigk 2010).

\section{d. The role of sea ice}

Since sea ice cover governs the interaction between atmosphere and ocean with regard to variability on various time scales, we will test the effect of SIA on the various correlations. As the difference between the $0.25 \times \mathrm{CO}_{2}$ and the other runs is largest on decadal time scales, Fig. 9 shows the correlation coefficient between 


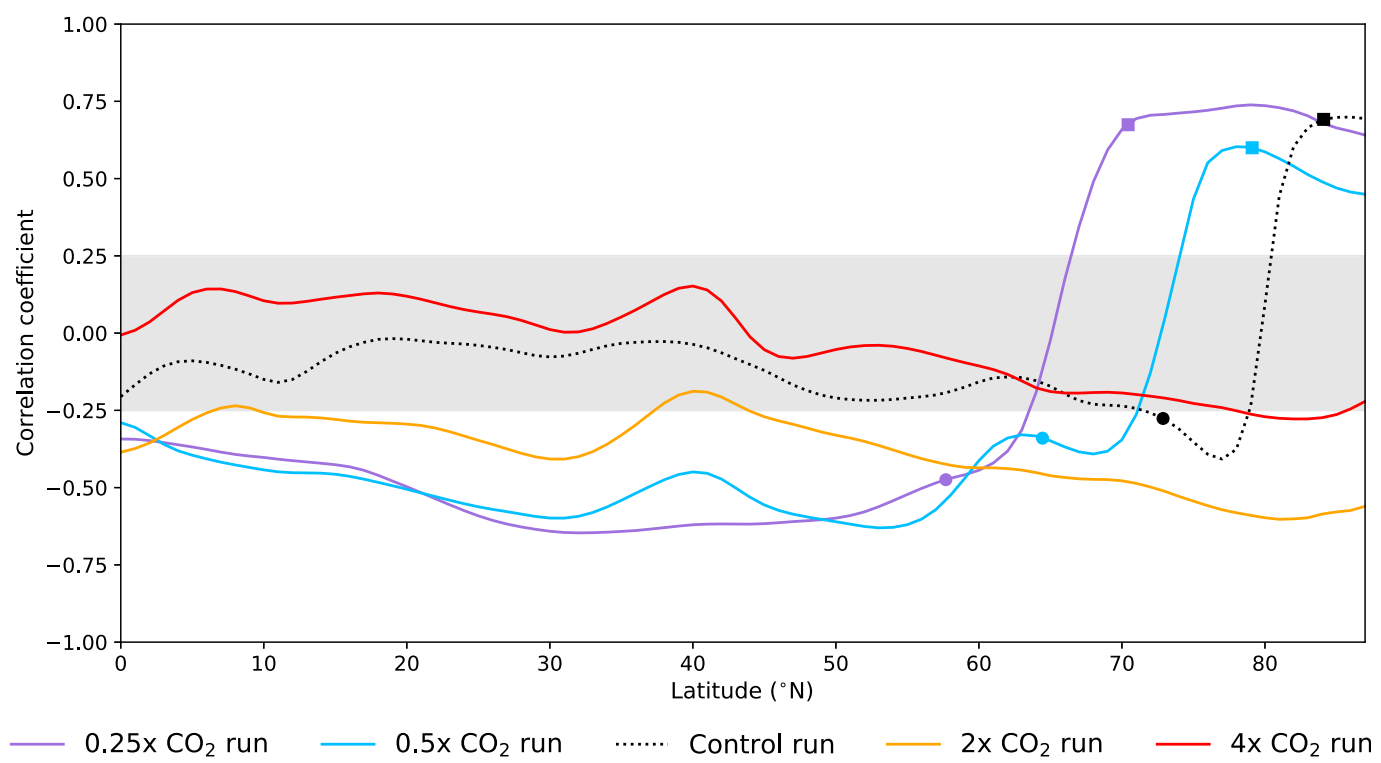

FIG. 9. Correlation between AHT through a latitude (indicated on the $x$ axis) and the average temperature in the Arctic $\left(70^{\circ}-90^{\circ} \mathrm{N}\right)$ for variations on decadal time scales. The circles denote the latitude of the sea ice edge on the Atlantic side $\left(60^{\circ} \mathrm{W}-30^{\circ} \mathrm{E}\right)$, where the sea ice edge is defined by the $15 \%$ isopleth. The squares denote a different sea ice edge, defined by the $90 \%$ isopleth. Correlations are again calculated with a zero time lead/lag. Insignificant correlations are calculated as in Fig. $8(p=0.99)$ and shaded.

AHT through a specific latitude and SAT in the Arctic for decadal variability. The circles denote the latitude of the sea ice edge on the Atlantic side $\left(60^{\circ} \mathrm{W}-30^{\circ} \mathrm{E}\right)$, where the sea ice edge is defined by the $15 \%$ isopleth. The squares denote a different sea ice edge, defined by the $90 \%$ isopleth. Because smoothing raises the correlation, a block bootstrap significance test with 1000 samples has been done (as described in section 3c). Correlations are found to be significant above 0.25 .

The three coldest climates exhibit a sudden increase in correlation toward the Arctic. The range of latitudes that span this transition varies from $60^{\circ}-70^{\circ} \mathrm{N}$ in the $0.25 \times \mathrm{CO}_{2}$ climate to $80^{\circ}-85^{\circ} \mathrm{N}$ in the control climate. We infer that positive correlations are found between AHT and SAT from this latitude onward, also on decadal time scales. At these latitudes, the sea ice present is perennial and inhibits exchange from the ocean to the atmosphere all year round. This is in agreement with results discussed in section $3 \mathrm{~b}$. The absence of a sudden increase in the two warm climates is due to the absence of perennial ice. Negative correlations at lower latitudes are likely a result of the previously described Bjerknes compensation.

\section{e. Leads and lags}

Even though correlations are insightful to identify possible climate links behind Arctic variability, studying leads/lags will provide better insight into the governing physical mechanisms. Figure 10 shows the correlation between two variables for different leads and lags. The significant maxima and minima are denoted by circles.

Leads and lags for interannual variability (Fig. 10, lefthand side panels) are consistent across all climates. Clearly, the atmospheric heat transport is positively correlated to, and also leads, interannual temperature variability (Fig. 10a). Significant correlations are found for all climates, with maximum correlations for a leading atmosphere. The lag increases for higher $\mathrm{CO}_{2}$ runs and is hypothesized to be related to the open ocean area. Open water acts as a buffer, thereby delaying the atmospheric response. Across all climates, OHT also leads interannual SAT variations, with negative correlations up to -0.59 in the $0.25 \times \mathrm{CO}_{2}$ and $4 \times \mathrm{CO}_{2}$ runs (Fig. 10b). This suggests that both the atmosphere and the ocean are leading fluctuations in SAT.

Decadal variability exhibits a more ambiguous story (Fig. 10, right-hand side panels). Now, SAT leads AHT, but only for 3 out of the 5 simulations (Fig. 10c). Correlations are significant for all climates, with 4 out of the 5 runs showing negative correlations. Out of these four runs, positive lags are present for 3 out of the 4 experiments. It is unclear why the maximum correlation between SAT and AHT in the $2 \times \mathrm{CO}_{2}$ run is found for a negative lag. On the contrary, the largest correlation found is positive (above 0.6), for the $0.25 \times \mathrm{CO}_{2}$ run and a lag of -2 months. These positive correlations found between AHT and SAT in this climate are 
(a)

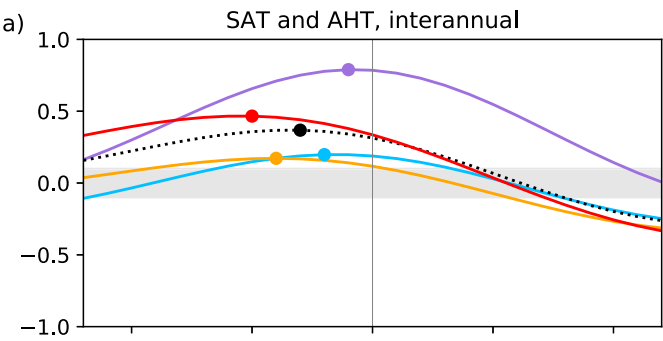

(b)

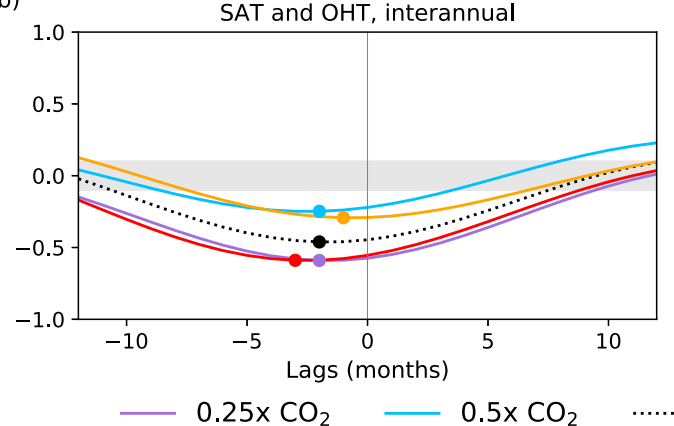

(c)

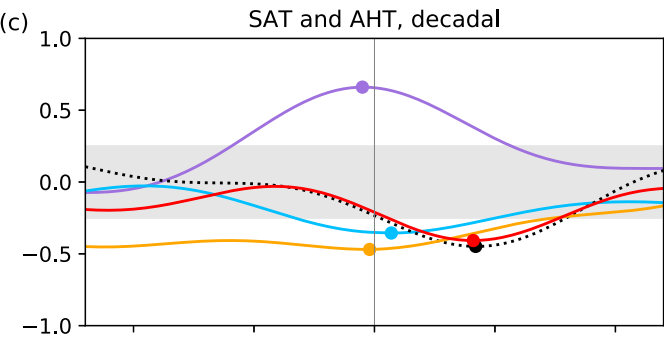

(d)

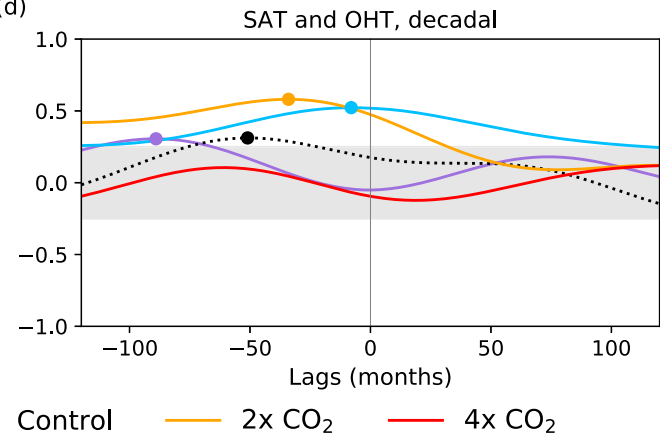

FIG. 10. Correlation between SAT and AHT or OHT for different leads/lags when (left) high frequencies and (right) low frequencies are selected. For positive lags, the first variable mentioned is leading. The shaded area marks the insignificant correlations that could arise due to the filtering of frequencies (as described in Fig. 8). The open circles represent the significant maximum correlations. Between -0.25 and 0.25 , correlations for decadal variability are insignificant, indicated by the shaded area. For interannual variations, this is between -0.10 and 0.10 . Note the difference in scale on the $x$ axes.

explained earlier (see section 3b). Correlations between OHT and SAT are largest when OHT is leading and only insignificant for the $4 \times \mathrm{CO}_{2}$ simulation. The modified role of the oceans is exemplified in the coldest climate $(0.25 \times$ $\mathrm{CO}_{2}$ ). In this climate, the ocean is covered by a sea ice lid, as is also described in section $3 \mathrm{~d}$. The key role here is played by the sea ice, since it prevents transfer of heat and momentum between the ocean and the atmosphere in the coldest climate. No clear reasons are found for the weak (although still significant) correlation between SAT and OHT in the control climate.

\section{Discussion and conclusions}

In this study, the dependence of Arctic variability on the time scale and the state of the climate is investigated using five coupled model simulations with $0.25 \times, 0.5 \times$, $1 \times, 2 \times$, and $4 \times$ the present-day $\mathrm{CO}_{2}$ concentration. This paper focuses on the link between Arctic temperature variability and heat transport toward the Arctic through the atmosphere and ocean and its dependence on the climate state. It is important to keep in mind that these heat transports are not the only processes impacting Arctic variability, since local feedback mechanisms also play an important role (Bintanja and Selten 2014). We focus on variability on time scales ranging from interannual to (multi-)decadal.
Assessing interannual to decadal variability of long observational records is difficult, since the temporal resolution of proxies (data gathered by natural recorders, e.g., ice cores) is too coarse and incomplete or missing, especially over the central Arctic. We therefore rely on models and the model quality and parameterizations, especially when using one model as done here. We focus on the physical processes behind climate variability, so that the findings obtained with this one model will likely be applicable more generically.

In determining the origin of Arctic temperature variability, temperature variability is linked to anomalies in heat transport. First, the mean state is investigated. On average, atmospheric heat transport decreases toward warmer climates, whereas oceanic heat transport increases. In a warmer climate, the meridional temperature gradient between the equator and the poles is decreased because of Arctic amplification (Holland and Bitz 2003), reducing the annual mean atmospheric heat transport. In the ocean, a combination of higher water temperatures and large-scale circulation changes enable the transport of more heat. The net effect is an increase in variability in poleward ocean heat transport in warmer climates. Variability in atmospheric heat transport increases toward warmer climate states, likely due to the increased moisture holding capacity of a warmer atmosphere (Mortin et al. 2016), in contrast to the average 
atmospheric heat transport. The difference in variability between the five climates is most clear on interannual time scales. On decadal time scales, the results are more ambiguous, with a decrease in variability in both atmospheric and oceanic heat transport in the $4 \times \mathrm{CO}_{2}$ climate as compared to the $2 \times \mathrm{CO}_{2}$ simulation.

Arctic temperature variability highly depends on the state of the climate, with interannual variability in SAT increasing toward colder climates. Decadal variability in general follows the same pattern, with the exception of an increase in variability in the $2 \times \mathrm{CO}_{2}$ run, caused to a large extent by the increased decadal variability in the surface fluxes. On interannual time scales, an increasing link between temperature and the $\mathrm{AO}$ has been found for the climates containing $2 \times$ and $4 \times \mathrm{CO}_{2}$, suggesting a more prominent role of the $\mathrm{AO}$ when the amount of sea ice decreases. This is in contrast with Holland and Stroeve (2011), who find a decreasing relationship between summer atmospheric circulation and September sea ice extent. This decrease or increase seems to be primarily related to a shift in the location of largest sea ice variability (Goosse and Holland 2005; Holland and Stroeve 2011; van der Linden et al. 2017), which cause changes in surface fluxes, resulting in altered pressure patterns. Sea ice variability itself is determined by many factors (Comiso 2006; Francis and Hunter 2006; Eisenman 2010) and has a central role, as is evident by the strong coupling between temperature and sea ice area, mostly through its impact on the surface fluxes (Selivanova et al. 2016). This coupling also determines to what extent oceanic and atmospheric heat transport modulate the variability in Arctic temperature on decadal time scales. Sea ice acts as a lid, inhibiting exchange between the ocean and the atmosphere. In a climate in which the Arctic is fully covered by sea ice, this lid prevents the ocean from passing along its variability to the atmosphere. As a result, it leaves the atmosphere to be driving variability also on decadal time scales. In an Arctic devoid of sea ice, ocean heat transport does not show a correlation to Arctic surface air temperature variability on any time scale. This shows that characteristics of climate variability will change fundamentally when the climate changes, an important aspect that needs to be taken into account in attributing climate changes to human influence.

Decadal climate variability has the ability to obscure or amplify anthropogenically induced trends, making its understanding of key importance in a globally warming world. At the same time, interannual variability and its state dependency are important in assessing the occurrence and magnitude of yearly extremes. This paper shows the clear difference and need to distinguish between interannual and decadal variability of temperature and sea ice area. Previously, variability on both interannual (e.g., Zhang and Li 2017; Caian et al. 2018) and decadal (e.g.,

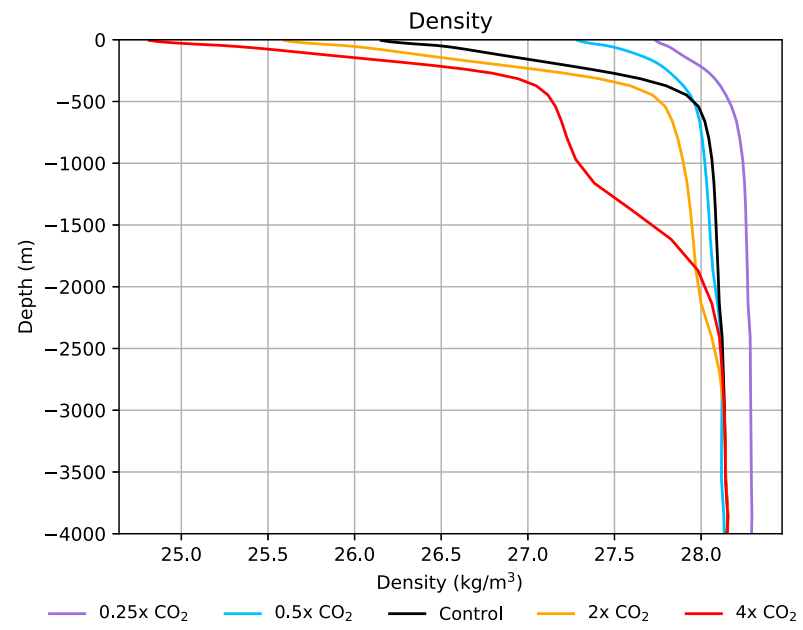

FIG. A1. Average Arctic Ocean density as a function of depth. Only points with depths larger than $500 \mathrm{~m}$ are taken. In the two warm climates, the deep ocean is not yet in equilibrium.

Day et al. 2012; van der Linden et al. 2017) time scales have been investigated separately, but this is the first time that its time scale dependence is quantified. We acknowledge that these results are solely based on EC-Earth. Other models might behave differently. For example, Ilıcak et al. (2016) show that there is large spread in temperature bias in the Arctic Ocean between state-of-the-art ocean climate models for realistic atmospheric forcing. Moreover, Day et al. (2012) found that variability in models exhibit strong intermodal differences. Nevertheless the results are robust and help gain better insight in how variability may change depending on its time scale and the state of the climate.

Acknowledgments. We are grateful to Dewi le Bars for helping out with the calculation of the density profiles as produced by NEMO. We would also like to thank Cees de Valk for providing feedback on the statistics. We are grateful to the EC-Earth consortium for their contribution to the development of the Earth System Model EC-Earth. Finally, we thank the three anonymous reviewers for helping to improve the manuscript.

\section{APPENDIX A}

\section{Additional Figures}

This appendix contains Figs. A1 and A2 .

\section{APPENDIX B}

\section{Validation Atmospheric Dynamics EC-Earth}

It is useful to validate the representation of the atmospheric dynamics in EC-Earth. To do this, the Arctic Oscillation (AO) index has been calculated as the principal component of the first EOF of the mean sea 

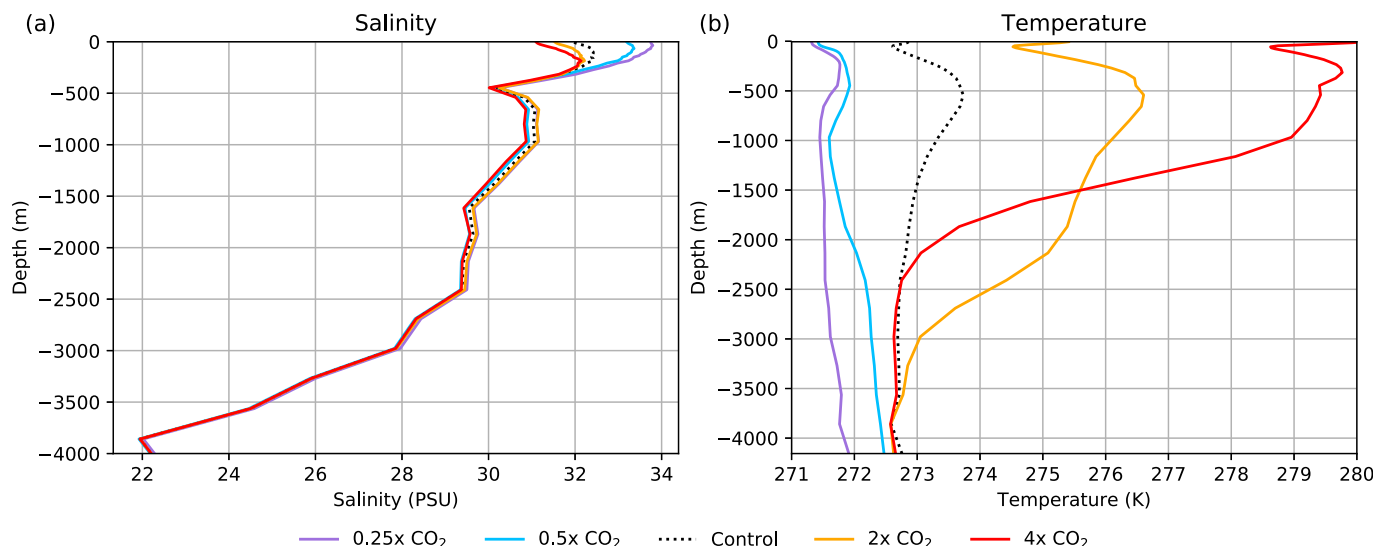

FIG. A2. Average Arctic Ocean (a) salinty and (b) temperature as a function of depth. Only the data points with depths larger than $500 \mathrm{~m}$ are considered (as in Fig. A1). Temperatures in the $4 \times \mathrm{CO}_{2}$ climate are able to reach much higher values, because of the absence of sea ice (more energy can be used to heat the water). The salinity difference is most pronounced in the first few hundred meters. On average, salinity becomes smaller toward warmer climates.

level pressure from $20^{\circ}$ to $90^{\circ} \mathrm{N}$ for the control run of EC-Earth and for the detrended reanalysis datasets for the period 1981-2010. A regression of the mean sea level pressure on the AO index reveals differences in spatial patterns (Figs. B1a-c). Both datasets show a clear anomaly over the central Arctic, with opposite pressure anomalies at lower latitudes on the Atlantic and Pacific side. The anomalies on the Atlantic side and over
Siberia are underestimated in EC-Earth. Overall, the fingerprint of the $\mathrm{AO}$ on the mean sea level pressure is more confined to higher latitudes in EC-Earth as compared to the reanalyses datasets. As for the effect of the $\mathrm{AO}$ on the temperature, we infer that there is an underestimation of the temperature anomaly over North America and Greenland and a more northerly extended anomaly over Siberia (Figs. B1d-f). In the end, we
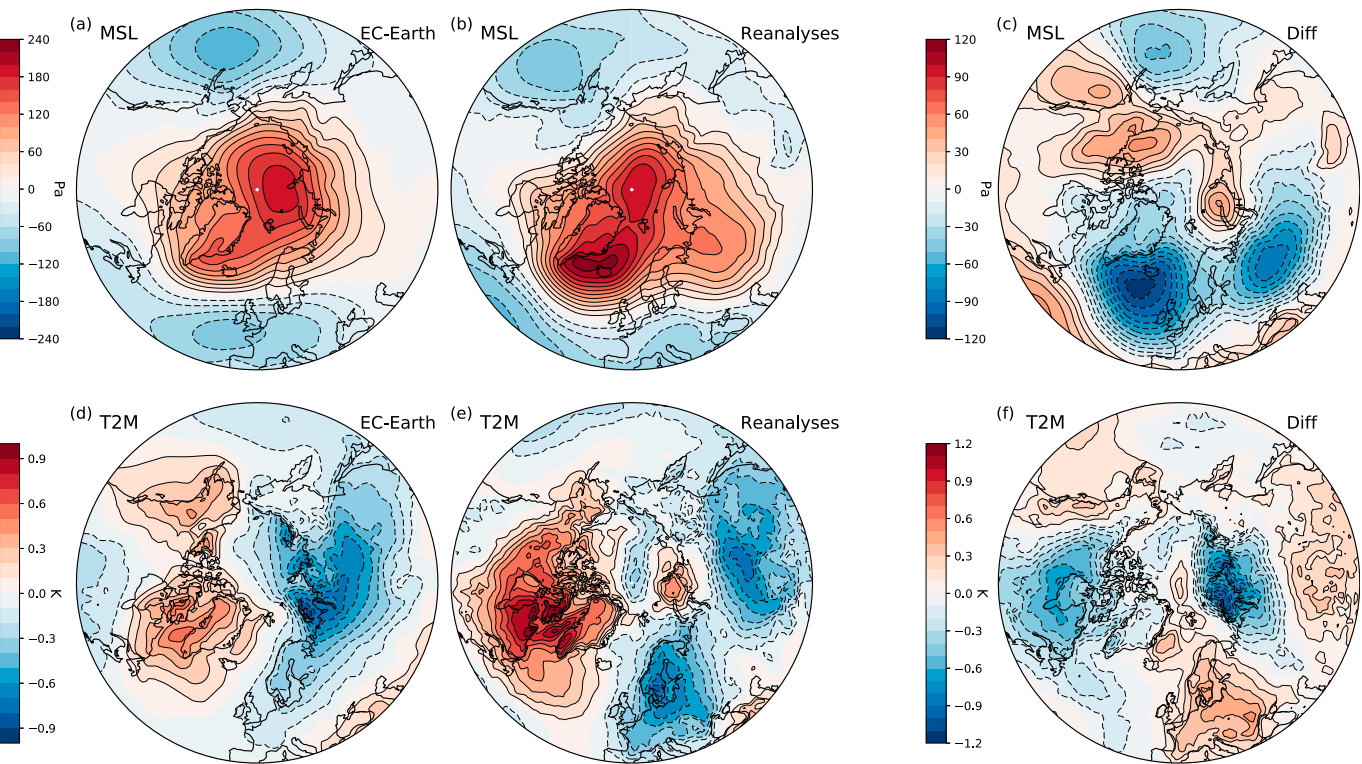

FIG. B1. Regression of (top) the mean sea level pressure and (bottom) the surface air temperature on the normalized AO index (the principal component of the first EOF of the mean sea level pressure over $20^{\circ}-90^{\circ} \mathrm{N}$ ), in $\mathrm{Pa}$ and Kelvin, for (a),(d) the control run of EC-Earth; (b),(e) detrended reanalyses data over the period 1981-2010; and (c),(f) the difference between the two. The reanalyses data are composed of the average of the ERA-Interim (Dee et al. 2011), NCEP/CSFR (Saha et al. 2010), and NASA MERRA-2 (Gelaro et al. 2017) reanalyses. 
conclude that the AO is represented reasonably well, since the general patterns are similar.

\section{REFERENCES}

Årthun, M., and T. Eldevik, 2016: On anomalous ocean heat transport toward the Arctic and associated climate predictability. J. Climate, 29, 689-704, https://doi.org/10.1175/ JCLI-D-15-0448.1.

Balsamo, G., A. Beljaars, K. Scipal, P. Viterbo, B. van den Hurk, M. Hirschi, and A. K. Betts, 2009: A revised hydrology for the ECMWF model: Verification from field site to terrestrial water storage and impact in the Integrated Forecast System. J. Hydrometeor., 10, 623-643, https://doi.org/10.1175/ 2008JHM1068.1.

Bintanja, R., and E. van der Linden, 2013: The changing seasonal climate in the Arctic. Sci. Rep., 3, 1556, https://doi.org/10.1038/ srep01556.

— linked to local evaporation and sea-ice retreat. Nature, 509, 479-482, https://doi.org/10.1038/nature13259.

_- R. S. van de Wal, and J. Oerlemans, 2005: Modelled atmospheric temperatures and global sea levels over the past million years. Nature, 437, 125-128, https://doi.org/10.1038/ nature 03975 .

Bjerknes, J., 1964: Atlantic air-sea interaction. Advances in Geophysics, Vol. 10, Academic Press, 1-82, https://doi.org/ 10.1016/S0065-2687(08)60005-9.

Caian, M., T. Koenigk, R. Döscher, and A. Devasthale, 2018: An interannual link between Arctic sea-ice cover and the North Atlantic Oscillation. Climate Dyn., 50, 423-441, https:// doi.org/10.1007/s00382-017-3618-9.

Chylek, P., J. Li, M. Dubey, M. Wang, and G. Lesins, 2011: Observed and model simulated 20th century Arctic temperature variability: Canadian earth system model CanESM2. Atmos. Chem. Phys. Discuss., 11, 22 893-22 907, https://doi.org/10.5194/ acpd-11-22893-2011.

Comiso, J. C., 2006: Abrupt decline in the Arctic winter sea ice cover. Geophys. Res. Lett., 33, L18504, https://doi.org/10.1029/ 2006GL027341.

_ , 2017: Bootstrap sea ice concentrations from Nimbus-7 SMMR and DMSP SSM/I-SSMIS, version 3. Monthly NH data used. Boulder, NASA National Snow and Ice Data Center Distributed Active Archive Center, accessed February 2018, https://doi.org/10.5067/7Q8HCCWS4I0R.

_ from space. Wiley Interdiscip. Rev.: Climate Change, 5, 389409, https://doi.org/10.1002/wcc.277.

Curry, J. A., J. L. Schramm, and E. E. Ebert, 1995: Sea ice-albedo climate feedback mechanism. J. Climate, 8, 240-247, https:// doi.org/10.1175/1520-0442(1995)008<0240:SIACFM >2.0.CO;2.

Day, J., J. Hargreaves, J. Annan, and A. Abe-Ouchi, 2012: Sources of multi-decadal variability in Arctic sea ice extent. Environ. Res. Lett., 7, 034011, https://doi.org/10.1088/1748-9326/7/3/034011.

Dee, D. P., and Coauthors, 2011: The ERA-Interim reanalysis: Configuration and performance of the data assimilation system. Quart. J. Roy. Meteor. Soc., 137, 553-597, https://doi.org/ 10.1002/qj.828.

deMenocal, P., J. Ortiz, T. Guilderson, and M. Sarnthein, 2000: Coherent high-and low-latitude climate variability during the Holocene warm period. Science, 288, 2198-2202, https:// doi.org/10.1126/science.288.5474.2198.
Dijkstra, H., 2008: Dynamical Oceanography. Springer, 407 pp.

Eisenman, I., 2010: Geographic muting of changes in the Arctic sea ice cover. Geophys. Res. Lett., 37, L16501, https://doi.org/ 10.1029/2010GL043741.

Fichefet, T., and M. Maqueda, 1997: Sensitivity of a global sea ice model to the treatment of ice thermodynamics and dynamics. J. Geophys. Res., 102, 12 609-12 646, https://doi.org/10.1029/ 97JC00480.

Francis, J. A., and E. Hunter, 2006: New insight into the disappearing Arctic sea ice. Eos, Trans. Amer. Geophys. Union, 87, 509-511, https://doi.org/10.1029/2006EO460001.

Frankignoul, C., N. Sennéchael, and P. Cauchy, 2014: Observed atmospheric response to cold season sea ice variability in the Arctic. J. Climate, 27, 1243-1254, https://doi.org/10.1175/ JCLI-D-13-00189.1.

Ganopolski, A., S. Rahmstorf, V. Petoukhov, and M. Claussen, 1998: Simulation of modern and glacial climates with a coupled global model of intermediate complexity. Nature, 391, 351-356, https://doi.org/10.1038/34839.

Gelaro, R., and Coauthors, 2017: The Modern-Era Retrospective Analysis for Research and Applications, version 2 (MERRA-2). J. Climate, 30, 5419-5454, https://doi.org/10.1175/ JCLI-D-16-0758.1.

Goosse, H., and T. Fichefet, 1999: Importance of ice-ocean interactions for the global ocean circulation: A model study. J. Geophys. Res., 104, 23 337-23 355, https://doi.org/10.1029/1999JC900215.

, and M. M. Holland, 2005: Mechanisms of decadal Arctic climate variability in the Community Climate System Model, version 2 (CCSM2). J. Climate, 18, 3552-3570, https://doi.org/ 10.1175/JCLI3476.1.

, O. Arzel, C. M. Bitz, A. de Montety, and M. Vancoppenolle, 2009: Increased variability of the arctic summer ice extent in a warmer climate. Geophys. Res. Lett., 36, L23702, https:// doi.org/10.1029/2009GL040546.

Graversen, R. G., and M. Burtu, 2016: Arctic amplification enhanced by latent energy transport of atmospheric planetary waves. Quart. J. Roy. Meteor. Soc., 142, 2046-2054, https:// doi.org/10.1002/qj.2802.

—, P. L. Langen, and T. Mauritsen, 2014: Polar amplification in CCSM4: Contributions from the lapse rate and surface albedo feedbacks. J. Climate, 27, 4433-4450, https://doi.org/10.1175/ JCLI-D-13-00551.1.

Hansen, J., R. Ruedy, M. Sato, and K. Lo, 2010: Global surface temperature change. Rev. Geophys., 48, RG4004, https:// doi.org/10.1029/2010RG000345.

Hazeleger, W., and Coauthors, 2012: EC-Earth V2.2: Description and validation of a new seamless earth system prediction model. Climate Dyn., 39, 2611-2629, https://doi.org/10.1007/ s00382-011-1228-5.

Holland, M. M., 2003: The North Atlantic Oscillation-Arctic Oscillation in the CCSM2 and its influence on Arctic climate variability. J. Climate, 16, 2767-2781, https://doi.org/10.1175/ 1520-0442(2003)016<2767:TNAOOI $>2.0 . \mathrm{CO} ; 2$.

- and C. M. Bitz, 2003: Polar amplification of climate change in coupled models. Climate Dyn., 21, 221-232, https://doi.org/ 10.1007/s00382-003-0332-6.

_ relationships in a changing Arctic climate. Geophys. Res. Lett., 38, L18501, https://doi.org/10.1029/2011GL049303.

Hurrell, J. W., Y. Kushnir, G. Ottersen, and M. Visbeck, 2003: An overview of the North Atlantic Oscillation. The North Atlantic Oscillation: Climatic Significance and Environmental Impact, Geophys. Monogr., Vol. 134, Amer. Geophys. Union, 1-35. 
Hwang, Y.-T., D. M. Frierson, and J. E. Kay, 2011: Coupling between arctic feedbacks and changes in poleward energy transport. Geophys. Res. Lett., 38, L17704, https://doi.org/ 10.1029/2011GL048546.

Ilicak, M., and Coauthors, 2016: An assessment of the arctic ocean in a suite of interannual CORE-II simulations. Part III: Hydrography and fluxes. Ocean Modell., 100, 141-161, https:// doi.org/10.1016/j.ocemod.2016.02.004.

IPCC, 2014: Climate Change 2014: Impacts, Adaptation, and Vulnerability. Part A: Global and Sectoral Aspects. Cambridge University Press, 1132 pp., https://doi.org/10.1017/CBO9781107415379

Jungclaus, J. H., and T. Koenigk, 2010: Low-frequency variability of the arctic climate: The role of oceanic and atmospheric heat transport variations. Climate Dyn., 34, 265-279, https:// doi.org/10.1007/s00382-009-0569-9.

Kinnard, C., C. M. Zdanowicz, D. A. Fisher, E. Isaksson, A. de Vernal, and L. G. Thompson, 2011: Reconstructed changes in Arctic sea ice over the past 1,450 years. Nature, 479, 509, https://doi.org/10.1038/nature10581.

Madec, G., 2008: NEMO ocean engine. Note du Pole de modelisation 27, Institut Pierre-Simon Laplace, 209 pp.

Manabe, S., and R. T. Wetherald, 1980: On the distribution of climate change resulting from an increase in $\mathrm{CO} 2$ content of the atmosphere. J. Atmos. Sci., 37, 99-118, https://doi.org/ 10.1175/1520-0469(1980)037<0099:OTDOCC >2.0.CO;2.

Mantua, N. J., and S. R. Hare, 2002: The Pacific Decadal Oscillation. J. Oceanogr., 58 35-44, https://doi.org/10.1023/A: 1015820616384.

Mayewski, P. A., and Coauthors, 2004: Holocene climate variability. Quat. Res., 62, 243-255, https://doi.org/10.1016/ j.yqres.2004.07.001.

Mortin, J., G. Svensson, R. G. Graversen, M.-L. Kapsch, J. C. Stroeve, and L. N. Boisvert, 2016: Melt onset over Arctic sea ice controlled by atmospheric moisture transport. Geophys. Res. Lett., 43, 6636-6642, https://doi.org/10.1002/2016GL069330.

Nakamura, N., and A. H. Oort, 1988: Atmospheric heat budgets of the polar regions. J. Geophys. Res., 93, 9510-9524, https:// doi.org/10.1029/JD093iD08p09510.

Outten, S., and I. Esau, 2017: Bjerknes compensation in the Bergen climate model. Climate Dyn., 49, 2249-2260, https://doi.org/ 10.1007/s00382-016-3447-2.

,-- , and O. H. Otterå, 2018: Bjerknes compensation in the CMIP5 climate models. J. Climate, 31, 8745-8760, https:// doi.org/10.1175/JCLI-D-18-0058.1.

Rehfeld, K., T. Münch, S. L. Ho, and T. Laepple, 2018: Global patterns of declining temperature variability from the Last Glacial Maximum to the Holocene. Nature, 554, 356, https:// doi.org/10.1038/nature25454.

Rind, D., R. Healy, C. Parkinson, and D. Martinson, 1997: The Role of sea ice in $2 \times \mathrm{CO} 2$ climate model sensitivity: Part II: Hemispheric dependencies. Geophys. Res. Lett., 24, 14911494, https://doi.org/10.1029/97GL01433.
Saha, S., and Coauthors, 2010: The NCEP Climate Forecast System Reanalysis. Bull. Amer. Meteor. Soc., 91, 1015-1058, https:// doi.org/10.1175/2010BAMS3001.1.

Screen, J. A., and I. Simmonds, 2010: The central role of diminishing sea ice in recent Arctic temperature amplification. Nature, 464, 1334-1337, https://doi.org/10.1038/nature09051.

Selivanova, J., N. Tilinina, S. Gulev, and S. Dobrolubov, 2016: Impact of ice cover in the Arctic on ocean-atmosphere turbulent heat fluxes. Oceanology, 56, 14-18, https://doi.org/ 10.1134/S0001437016010185.

Serreze, M. C., and R. G. Barry, 2011: Processes and impacts of Arctic amplification: A research synthesis. Global Planet. Change, 77, 85-96, https://doi.org/10.1016/j.gloplacha.2011.03.004. , A. P. Barrett, A. G. Slater, M. Steele, J. Zhang, and K. E. Trenberth, 2007: The large-scale energy budget of the Arctic. J. Geophys. Res., 112, D11122, https://doi.org/10.1029/ 2006JD008230.

Taylor, K. E., R. J. Stouffer, and G. A. Meehl, 2012: An overview of CMIP5 and the experiment design. Bull. Amer. Meteor. Soc., 93, 485-498, https://doi.org/10.1175/BAMS-D-11-00094.1.

Trenberth, K. E., and J. M. Caron, 2001: Estimates of meridional atmosphere and ocean heat transports. J. Climate, 14, 34333443, https://doi.org/10.1175/1520-0442(2001)014<3433: EOMAAO $>2.0 . \mathrm{CO} ; 2$.

Valcke, S., A. Caubel, D. Declat, and L. Terray, 2003: OASIS3 ocean atmosphere sea ice soil user's guide. Prism Project Rep. 2.

van der Linden, E. C., R. Bintanja, W. Hazeleger, and R. G. Graversen, 2016: Low-frequency variability of surface air temperature over the Barents Sea: Causes and mechanisms. Climate Dyn., 47, 1247-1262, https://doi.org/10.1007/s00382-015-2899-0.

$\longrightarrow,-$, and -2017 : Arctic decadal variability in a warming world. J. Geophys. Res., 122, 5677-5696, https://doi.org/ 10.1002/2016JD026058.

—, D. Le Bars, R. Bintanja, and W. Hazeleger, 2019: Oceanic heat transport into the Arctic under high and low $\mathrm{CO} 2$ forcing. $\mathrm{Cli}$ mate Dyn., https://doi.org/10.1007/S00382-019-04824-Y, in press.

Van der Swaluw, E., S. Drijfhout, and W. Hazeleger, 2007: Bjerknes compensation at high northern latitudes: The ocean forcing the atmosphere. J. Climate, 20, 6023-6032, https:// doi.org/10.1175/2007JCLI1562.1.

Zhang, L., and T. Li, 2017: Physical processes responsible for the interannual variability of sea ice concentration in Arctic in boreal autumn since 1979. J. Meteor. Res., 31, 468-475, https:// doi.org/10.1007/s13351-017-6105-7.

Zhang, R., 2015: Mechanisms for low-frequency variability of summer Arctic sea ice extent. Proc. Natl. Acad. Sci. USA, 112, 4570-4575, https://doi.org/10.1073/pnas.1422296112.

Zhao, Y., H. Yang, and Z. Liu, 2016: Assessing Bjerknes compensation for climate variability and its time-scale dependence. J. Climate, 29, 5501-5512, https://doi.org/10.1175/ JCLI-D-15-0883.1. 